\title{
SISTEM PELACAK LOKASI SAPI DENGAN SISTEM KOMUNIKASI LORA
}

\author{
Randy Angriawan ${ }^{1}$, Nurhajar Anugraha ${ }^{2}$ \\ Teknik Informatika STMIK AKBA ${ }^{1,2}$ \\ Email: randy@akba.ac.id ${ }^{1}$,nurhajar@akba.ac.id ${ }^{2}$
}

\begin{abstract}
ABSTRAK
.Perkembangan teknologi komunikasi saat ini berkembang pesat terutama pada Internet of Things (IoT).Perkembangannya telah masuk dalam berbagai aspek kehidupan manusia, salah satu yang banyak dikembangkan adalah untuk efisiensi komunikasi pada pelacakan objek bergerak. Dari beberapa jenis komunikasi yang tersedia, komunikasi seluler merupakan yang umum dan banyak digunakan, namun kendala terbesar yang dihadapi, tidak semua daerah dapat terjangkau oleh jaringan seluler khususnya pada pedesaan. Untuk mengatasi masalah tersebut, dalam paper ini kami mengusulkan menggunakan Lora sebagia pengiriman data lokasi. LoRa mengirim data dari Node ke Gateway dan diteruskan ke internet. Dari hasil implementasi pegiriman data dari Node ke Gateway menunjukkan bahwa jarak berbanding lurus dengan dengan kehilangan data dan kekuatan sinyal (RSSI) meleamah. Sebagai contoh jarak $1 \mathrm{~km}$ dengan RSSI -98 jumlah paket hilang sekitar 2 dan jarak terjauh yaitu $2.5 \mathrm{~km}$ dengan RSSI 128 jumlah paket hilang sekitar 19.
\end{abstract}

Kata Kunci: Sistem Pelacak, sistem Komunikasi, LoRa.

\begin{abstract}
ABSTRCT
The development of communication technology is currently growing rapidly in the Internet of Things (IoT), it has developed in various aspects of human life. One of them is the efficiency of tracking mobile objects. There are many types of communication available. Cellular communication is one of the most common and widely used, but it has a problem like some locations are not covered by cellular networks. To overcome this problem, in this paper we proposed to use Lora for sending the location of the cow. LoRa sending data from Node to the Gateway and forwarded to the internet. The implementation results of sending data from Node to Gateway shows that the distance is directly proportional to the loss of data and signal strength (RSSI). For example, a distance of $1 \mathrm{~km}$ with the RSSI -98 the number of lost packages is around 2 and the furthest distance is $2.5 \mathrm{~km}$ with RSSI -128 the number of lost packages is about 19.
\end{abstract}

Keywords: Tracking System, Communication System, LoRa.

\section{PENDAHULUAN}

Internet of Things (IoT) merupakan teknologi baru untuk pertukaran informasi melalui jaringan, dimana perangkat dan berbagai objek dapat berkomunikasi satu sama lain dan dapat bertransformasi dari dunia maya ke dunia fisik (Shah and Yaqoob 2016), (Dragomir et al. 2016). Teknologi komunikasi pada IoT didukung dengan beragam arsitektur jaringan 
protokol dalam membantu komunikasi yang efisien. Berbagai perangkat telah terlibat dalam pengembangan IoT diantaranya perangkat mobile, komputer dan mesin (Anupriya K et al. 2016)

Teknologi komunikasi telah banyak diadopsi dan dikembangkan untuk kepentingan pemantauan dan pelacakan sebuah objek, seperti pemantauan gunung merapi, pemantauan daerah bawah laut dan luar angkasa serta pemantauan bendabenda bergerak. Penggunaan sebuah jaringan komunikasi didasari pada cakupan area, konsumsi daya, serta biaya implementasi untuk menciptakan komunikasi yang efisien pada kondisi dan sebuah studi kasus tertentu (Anupriya K et al. 2016)

Pelacakan sebuah objek telah banyak dikembangkan untuk keperluan pribadi maupun keperluan masyarakat umum, seperti pelacakan kendaraan, manusia, dan hewan. Dari beberapa pelacakan yang telah disebutkan, jenis komunikasi yang digunakan sangat beragam, namun yang paling umum digunakan adalah seluler. Hal ini dikarenakan implementasi yang mudah dan telah banyak dikembangkan pada studi akhir-akhir ini.

Populasi sapi disebuah peternakan yang banyak mengharuskan pengelolah untuk bekerja ekstra dalam menjaga dan mengurusi sapi-sapi mereka. Beberapa kegiatan rutin harian seperti membawa sapi ke ladang dan memantau keberadaan sapisapi agar tidak terlalu jauh dari kawanan, hingga membawa kembali ke kandang menjelang petang. Masalah yang sering dialami oleh peternak jika beberapa sapi meninggalkan kawanan sapi lainya, ketika hal ini terjadi maka peternak harus segera membawa ke kawanan untuk mencegah sapi terlalu jauh yang dapat mengakibatkan kehilangan atau kecurian ternak mereka.

Masalah keamaan sejak lama menjadi maslaah klasik dihampir semua tempattempat peternakan sapi, entah itu peternakan pribadi dengan 5 sampai 10 ekor sapi sampai pada peternakan ratusan ekor sapi. Solusi yang paling sederhana yang dapat dilakukan adalah dengan penambahan pekerja oleh peternak untuk menjaga dan memaksimalkan pemeliharaan sapi-sapi meraka. Tapi dengan penambahan pekerja akan menimbulkan biaya operasional yang membengkak karena peternak harus membayar gaji untuk semua pekerja. Masalah lain terjadi pada peternak pribadi, yang tidak mampu untuk menggaji pekerja dikarenakan jumlah sapi yang tidak banya maka mereka harus mengurusi sapi-sapi mereka sendiri.

Kasus pencurian sapi akhir-akhir ini telah banyak terjadi terutama bagi peternak kampung, yang masih dengan cara-cara konvensional. Dipagi hari mereka membawa sapi-sapi mereka ke ladang, terkadang beberapa mereka hanya mengikat di pohon-pohon sekitar agar tidak menjauh, dan meninggalkannya beberapa waktu hingga menjelang petang lalu membawa pulang kembali.

Dari permasalahan tersebut, maka dibuatlah sebuah alat yang dapat membantu dalam pelacakan sapi agar peternak dapat memantau sapi-sapi mereka. Pemantaun dapat dilakukan di rumah-rumah mereka, sehingga para peternak bisa melakukan kegiatan yang lain dan pada saat ada hal yang mencurigakan pada hewan ternak mereka, mereka maka dapat segera ditindak lanjuti. 


\section{LANDASAN TEORI}

\section{A. Internet of Things}

Komunikasi antar perangkat komputer dengan sebuah objek merupakan fondasi utama dan merupakan awal mula pengembangan konsep dan realisasi dari Internet of Things secara lengkap, Protokol komunikasi memberikan akses dan kemampuan untuk berkomunikasi antara perangkat, sensor, mesin dan dunia luar (Bhuvaneswari and Porkodi 2014). Protokol komunikasi terdapat pada layer network yang bertanggung jawab pada bagian transfer informasi melalui teknologi jaringan seperti, GSM, 3G, 4G, UMTS, WiFi,ZigBee, Infrared, Z-Wire, LoRa, 6LoWPAN (Shah and Yaqoob 2016). Berbagai macam teknologi jaringan yang tersedia memiliki karasteristik dan kemampuan yang berbeda-beda dalam hal mentransfer informasi, konsumsi daya, cakupan area dan masalah keamanan data, hal ini diatur pada standar IEEE 802.15.4 (Dragomir et al. 2016).

\section{B. Arduino}

Arduino merupakan mikrokontroler single-Board yang open source dan input / Output sederhana dangan prosesor Atmel AVR. Perangkat lunak dari arduino menggunakan bahasa pemrograman yang sederhana (menyerupai bahasa C) dan dilengkapi dengan boot loader yang berjalan pada sebuah board. Board pada arduino menyediakan beberapa pin I / O (input / output) mikrokontroler sehingga dapat menghubungkan pin-pin tersebut ke sirkuit lain atau ke sensor (Mcroberts 2010).

\section{LoRa}

LoRa TM adalah Merek Dagang dan modulasi yang dikembangkan dipatenkan oleh Semtech Corporation. Modul LoRa beroperasi di band sub-GHz dengan daya pancar maksimum didefinisikan sebagai 14 dan 21,7 dBm di Eropa dan Amerika Serikat (USA: $433 \mathrm{MHz}$ and $915 \mathrm{MHz}, \mathrm{EU}$ : $433 \mathrm{MHz}$ and $868 \mathrm{MHz}$ ). Sistem LoRa terdiri dari end-devices, gateway, dan NetServer yang membentuk topologi star of stars dengan NetServer di root, Gateway di level awal atau sebagai control serta penerima informasi dari node dan enddevices sebagai sumber informasi atau perangkat yang menerima sebuah informasi dari luar sistem (Georgiou and Raza 2016).

LoRa adalah lapisan fisik atau modulasi nirkabel yang digunakan untuk menciptakan hubungan komunikasi jarak jauh. Banyak sistem wireless lawas menggunakan modulasi frequency syuting keying (FSK) sebagai lapisan fisik karena merupakan modulasi yang sangat efisien untuk mencapai daya rendah. LoRa didasarkan pada modulasi chirp spread spectrum, yang mempertahankan karakteristik daya rendah yang sama dengan modulasi FSK namun secara signifikan meningkatkan jangkauan komunikasi. LoraWan mendefinisikan protokol komunikasi dan arsitektur sistem untuk jaringan lapisan fisik LoRa yang memungkinkan jalur komunikasi jarak jauh. Protokol dan arsitektur jaringan memiliki pengaruh paling besar dalam menentukan masa pakai baterai suatu node, kapasitas jaringan, kualitas layanan, keamanan, dan beragam aplikasi yang dilayani oleh jaringan. Parameter yang disebutkan dapat menjadi pertimbangan dalam pengembangan sistem (LoRa Alliance 2015).

Dalam pengaplikasian LoRa, terdapat beberapa parameter yang dapat diatur oleh 
user untuk kebutuhan sistem yang akan dikembangkannyan, semisal kecepatan transfer data, jarak jangkauang, besar data dan konsumsi power. Parameter tersebut diantaranya adalah bandwidth (BW), spreading factor $(\mathrm{SF})$, coding rates (CR) and transmission powers (TP).

\section{Global Positioning System (GPS)}

Global Positioning System (GPS) adalah sebuah sistem penentuan letak di permukaan bumi dengan bantuan synchronization sinyal dari satelit. GPS sendiri merupakan bagian dari Global Navigation Satelit System (GNSS) yang menerima sinyal dari setidaknya tiga satelit untuk menghitung posisi lintang dan bujur dari sebuah objek. Dalam menentukan posisi, GPS membutuhkan paling sedikit 3 satelit untuk penentuan posisi 2 dimensi (lintang dan bujur) dan 4 satelit untuk penentuan posisi 3 dimensi (lintang, bujur, dan ketinggian). Dalam penuntuan posisi objek, GPS merupakan teknologi kunci dan solusi untuk mendapatkan posisi dari sebuah objek.GPS dalam sistem pelacakan digunakan untuk memberi pengguna koordinat lokasi di mana pun di bumi (Rahman et al. 2016).

\section{PERANCAANGAN SISTEM}

Pada bagian ini berisi tentang perancangan sistem yang dikembangkan, yaitu perancangan perangkat keras dan perancangan perangkat lunak. Untuk gambaran umum dari sistem yang dibuat dapat dilihat pada gambar 1 .

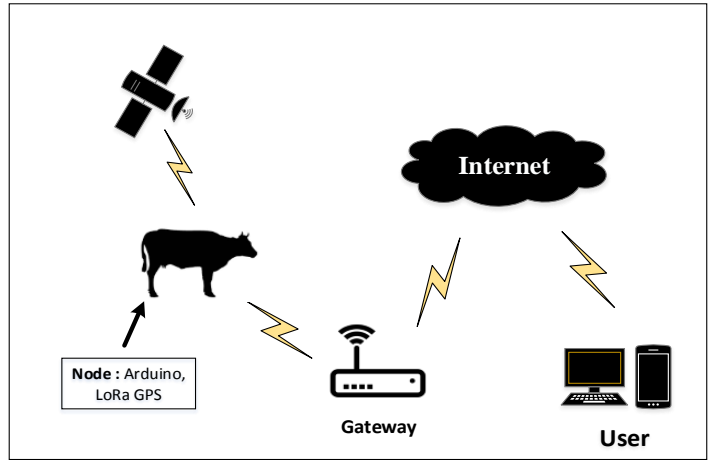

Gambar 1. Gambaran Umum Sistem

\section{A. Perancangan Perangkat Keras}

Peracangan perangkat keras terdiri dari dua bagian yaitu Node dan Gateway. Komponen pada Node meliputi Komponen pada Node-ILC meliputi Arduino Uno, Module GPS NEO-6M, Dragino LoRa Shield 915Mhz, external antenna $3 \mathrm{dBi}$. Untuk rancangan Node dapat dilihat pada gambar 3 .

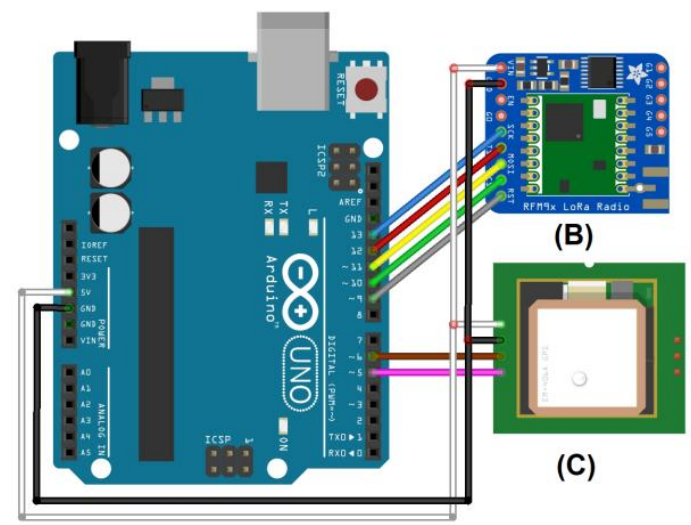

(A)

\section{Gambar 2. Node (A) Arduino(B) LoRa(C)GPS}

Untuk komponen pada Gateway meliputi Arduino Uno, Dragino LoRa Shield 915Mhz, Ground Plane Antenna FPV Telemetry, SIM900 Mini V4.0, rancangan Gateway dapat dilihat pada gambar 3 . 


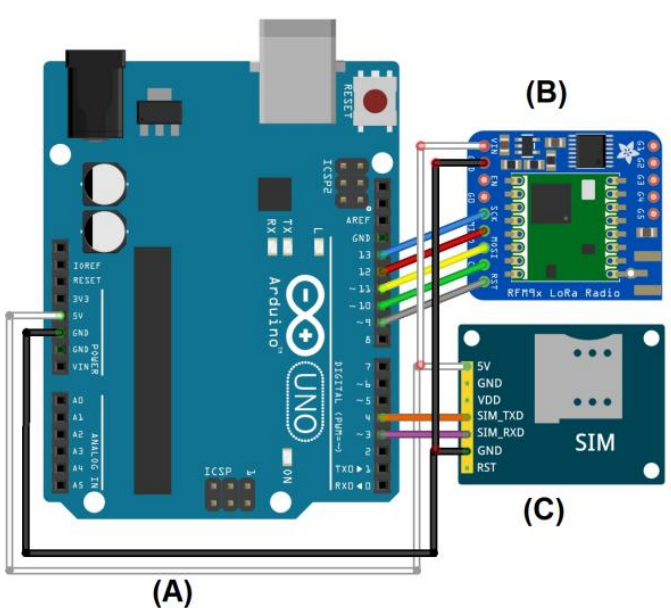

Gambar 3. Gateway (A) Arduino (B) LoRa (C) SIM

\section{B. Perancangan Perangkat Lunak}

Perangkat lunak Node-ILC dirancang untuk medapatkan lokasi terkini dari satelit dan mengirim lokasi tersebut ke Gateway, rancangan tersebut dapat dilihat pada gambar 3

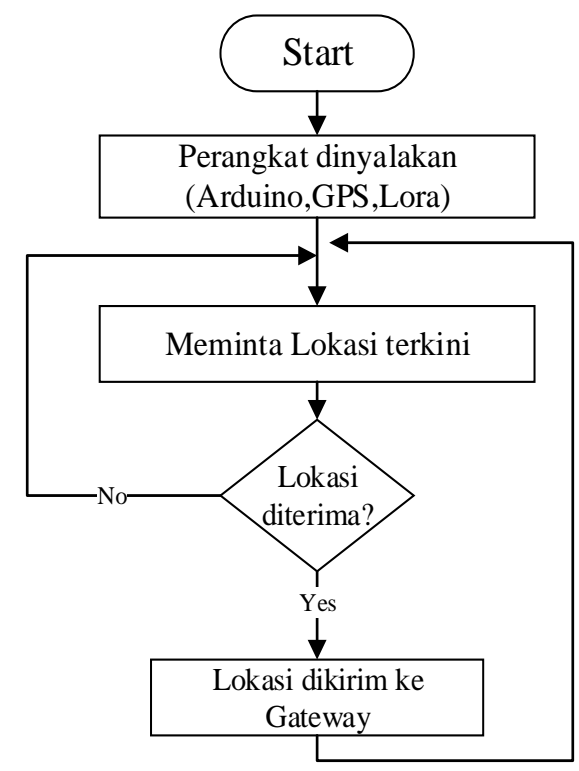

Gambar 4. Flowchar Node

Perangkat lunak Gateway dirancang untuk meneruskan paket dari Node ke internet. Untuk proses yang terjadi pada Gateway dilihat pada gambar 4.

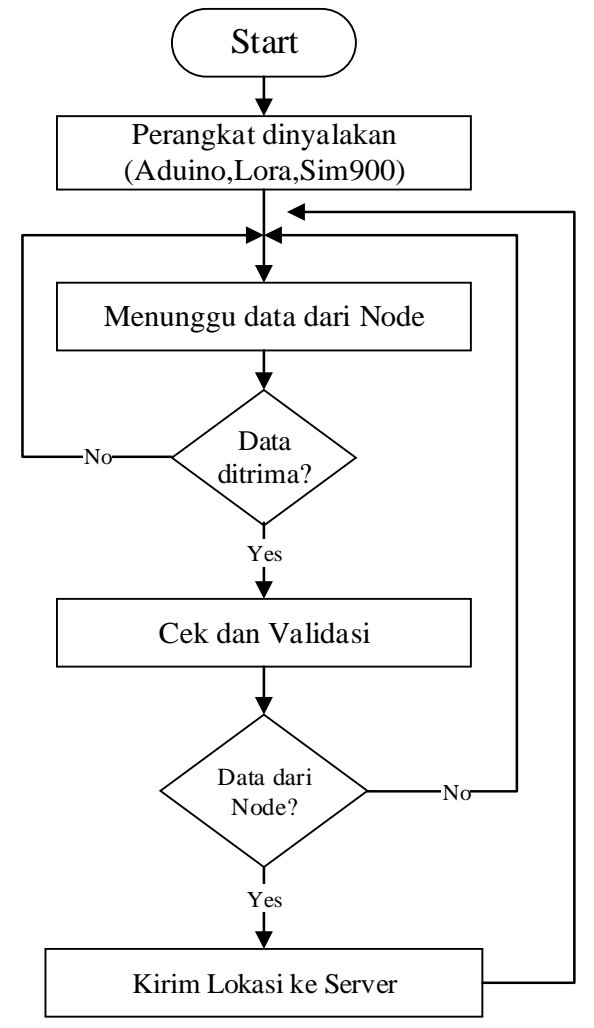

Gambar 5. Flowchar Gateway

\section{Skenario Pengujian}

Skenario uji coba dilakukan dengan mengirim data dari node ke gateway dan diteruskan ke cloud/internet. Data yang dikirim berupa lokasi kendaraan dan waktu terkini node dengan kapasitas data sebesar 45 byt. Lokasi uji coba dilakukan di Jl. Dusun Bilayya, Gowa, Sulawesi Selatan. Untuk konfigurasi LoRa yang digunakan dapat dilihat pada tabel 1

Tabel 1.Konfigurasi LoRa

\begin{tabular}{|l|c|}
\hline Konfigurasi Lora & Nilai Settingan \\
\hline Bandwidth & $125 \mathrm{kHz}$ \\
\hline Coding Rate & $4 / 5$ \\
\hline Spreading Factor & 7 \\
\hline Preamble Length & 8 \\
\hline TX Power & $13 \mathrm{dBm}$ \\
\hline
\end{tabular}




\section{HASIL DAN PEMBAHASAN}

Pada tabel 2 merupakan hasil pengujian pengiriman data dari node ke gateway dengan beberapa jarak yang berbeda dapat dilihat pada gambar 5 . Parameter yang diujia adalah RSSI (kekuatan sinyal) dan Paket hilang.

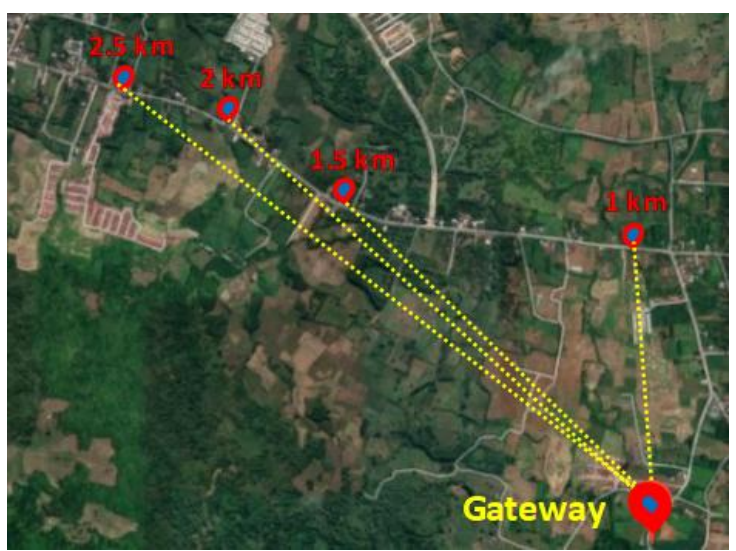

Gambar 6. Maps Jarak Node-Gateway

Hasil uji coba dengan jarak kurang lebih $1 \mathrm{~km}$ menujukkan level RSSI sekitar $98 \mathrm{dBm}$ dengan jumlah paket hilang yaitu 2. Untuk jarak kurang lebih $1.5 \mathrm{~km}$ menujukkan level RSSI sekitar $-113 \mathrm{dBm}$ dengan jumlah paket hilang 4. Untuk jarak kurang lebih $2 \mathrm{~km}$ menujukkan level RSSI sekitar $-119 \mathrm{dBm}$ dengan jumlah paket hilang yaitu 10. Untuk jarak kurang lebih $1.5 \mathrm{~km}$ menujukkan level RSSI sekitar -129 dBm dengan jumlah paket hilang yaitu 19 .

Tabel 2. Hasil Uji Coba Node-Gateway

\begin{tabular}{|l|c|c|c|c|}
\hline \multirow{2}{*}{ Keterangan } & \multicolumn{4}{|c|}{ Jarak (km) } \\
\cline { 2 - 5 } & $\mathbf{1}$ & $\mathbf{1 . 5}$ & $\mathbf{2}$ & $\mathbf{2 . 5}$ \\
\hline RSSI (dBm) & -98 & -106 & -117 & -128 \\
\hline Paket dikirim & 50 & 50 & 50 & 50 \\
\hline Paket diterima & 48 & 46 & 40 & 31 \\
\hline Paket hilang & 2 & 4 & 10 & 19 \\
\hline
\end{tabular}

Berdasarkan tabel 2 di atas, dapat di asumsikan bahwa jarak(km) memiliki pengaruh yang signifikan terhadap besarnya nilai RSSI (dBm) dan banyaknya paket yang hilang saat proses transmisi. Semakin jauh jarak antara Node ke Gateway maka RSSI (dBm) yang dihasilkan semakin besar dan kemungkinan paket hilang semakin besar pula.

\section{SIMPULAN DAN SARAN}

Kualitas pengiriman data merupakan bagian penting dalam pelacakan benda bergerak termasuk pada pelacakan sapi yang menjadi objek pada penelitian ini. Pengiriman data dengan LoRa merupakan salah satu alternatif yang dapat digunakan dengan jangkauan yang cukup jauh dan hemat energi. Hasil uji coba pengiriman data menunjukkan semakin jauh jarak antara Node dengan Gateway maka semakin besar pula kemungkinan paket hilang.

Untuk penelitian selanjutnya, diharapkan untuk memperbanyak node. Dengan bertambahnya node maka manajemen data akan semakin rumit dan perlu dikaji lebih dalam agar pengiriman data dari node ke gateway tidak mengalami kehilangan data yang signifikan.

\section{DAFTAR PUSTAKA}

Anupriya K et al. 2016. "Integrating ZigBee and Sub GHz Devices for Long Range Networks." 2016 Online International Conference on Green Engineering and Technologies (ICGET): $1-5$. http://ieeexplore.ieee.org/document/7 916826/.

Bhuvaneswari, V., and R. Porkodi. 2014. "The Internet of Things (IOT) Applications and Communication Enabling Technology Standards: An Overview." Proceedings - 2014 
International Conference on Intelligent Computing Applications, ICICA 2014: 324-29.

Dragomir, Dan, Laura Gheorghe, Sergiu Costea, and Alexandru Radovici. 2016. "2016 International Workshop on Secure Internet of Things A Survey on Secure Communication Protocols for IoT Systems."

LoRa Alliance. 2015. "A Technical Overview of LoRa and LoRaWAN." (November): 1-20. https://www.loraalliance.org/portals/0/documents/whit epapers/LoRaWAN101.pdf.

Mcroberts, Michael. 2010. Arduino. United States of America.

Rahman, Marufi, Jannatul Robaiat Mou, Kusum Tara, and Ismail Sarkar. 2016. "Real Time Google Map and Arduino Based Vehicle Tracking System." (December): 8-10.

Shah, Sajjad Hussain, and Ilyas Yaqoob. 2016. "A Survey: Internet of Things (IOT) Technologies, Applications and Challenges." 2016 IEEE Smart Energy Grid Engineering (SEGE) i: 381-85.

http://ieeexplore.ieee.org/document/7 589556/. 